\title{
Cold-shock eliminates female nucleus in fertilized eggs to induce androgenesis in the loach (Misgurnus anguillicaudatus), a teleost fish
}

\author{
Kagayaki Morishima1', Takafumi Fujimoto', Mami Sato', Ayako Kawae1, Yan Zhao1, Etsuro Yamaha² and \\ Katsutoshi Arai ${ }^{*}$
}

\begin{abstract}
Background: Androgenesis (all-male inheritance) is generally induced by means of irradiating the eggs to inactivate the maternal genome, followed by fertilization with normal sperm. In fish, the conventional technique for induced androgenesis has been applied for rapid fixation to traits, recovery of cryopreserved genotypes, sexcontrol, etc. A new method of androgenesis that eliminates the need to irradiate the egg was proposed using the loach, Misgurnus anguillicaudatus (a teleost fish).

Results: When the eggs of wild-type females were fertilized with sperm of albino or orange phenotype males and cold-shocked at 0 to $3^{\circ} \mathrm{C}$ for 60 min duration just after fertilization, generally more than 30\% (with a peak of 100\%) of the hatched progeny were androgenotes. While a few of them were the normal diploid, most of them turned out to be abnormal haploid. All-male inheritance was verified by the expression of the recessive color trait (albino or orange) and microsatellite genotypes comprising only paternally derived alleles. Nuclear behavior after the coldshock treatment was traced by microscopic observation of DAPI (4'6-diamidino-2-phenylindole)-stained samples and hematoxylin-eosin stained histological sections, and the extrusion of egg (maternal) nucleus was observed in eggs treated in the optimum timing.
\end{abstract}

Conclusion: In this paper, we demonstrate that cold-shock treatment (at 0 and $3^{\circ} \mathrm{C}$ ) of loach eggs for 60 min just after fertilization successfully induces androgenetic haploid development. The most likely mechanism of cold-shock induced androgenesis is an elimination of the egg nucleus together along with the second polar body and subsequent development of a decondensed sperm nucleus or male pronucleus.

\section{Background}

Androgenesis may be defined as uniparental reproduction without any genetic contribution from the maternally derived nucleus. In fish, artificial androgenesis has been induced by fertilization of genetically inactivated eggs with normal spermatozoa [1-4]. Genetic inactivation of egg nucleus has typically been achieved by means of irradiating the eggs with gamma- and X-rays, but more recently it has been shown that the egg nucleus can be successfully inactivated using ultraviolet (UV) irradiation, especially in fish with relatively smaller egg sizes [1-4]. In

\footnotetext{
* Correspondence: araikt@fish.hokudai.ac.jp

'Laboratory of Aquaculture Genetics and Genomics, Faculty and Graduate School of Fisheries Sciences, Hokkaido University, 3-1-1, Minato, Hakodate, Hokkaido, 041-8611, Japan

Full list of author information is available at the end of the article
}

aquaculture, cloning, rapid fixation of genotypes and sexcontrol (especially using super-male with YY genotype) are usually proposed by using genomes of completely homozygous doubled haploids, which are induced by chromosome duplication (endomitosis) at the first cleavage after the initiation of androgenetic development of haploid embryos [2,3]. Duplication of chromosomes in haploids is induced by temperature or pressure shock applied at the optimum timing of the pro-metaphase of the first mitotic cell division [5]. Homozygous clones have been produced in several fish species such as common carp [6], Nile tilapia [7], amago salmon [8], and rainbow trout [9]. Androgenesis is also regarded as a useful approach to recover genotypes from cryopreserved sperm of unique or endangered species [10]. Nagoya et al. [11] successfully produced viable androgenetic 
diploid amago salmon with gamma-irradiated eggs and subsequent dispermy fertilization using fusion of spermatozoa by PEG (polyethylene glycol). Similar attempts using induced androgenesis and fused spermatozoa or dispermy have also been reported in rainbow trout [12], barb [13], tetra [14] and sturgeon [15].

In clonally reproducing teleosts such as crucian carp and loach, a sperm nucleus that intrudes into an unreduced egg is never decondensed to form the male pronucleus, and gynogenetic development proceeds without any genetic contribution from the paternal genome [16,17]. Spontaneous gynogenesis (all-female inheritance) is fairly common in lower vertebrates, including teleosts $[18,19]$. In contrast, spontaneous androgenetic individuals (allmale inheritance) have never been reported in vertebrates, although the phenomenon is seen in a few invertebrates including the hermaphrodite triploid clam [20,21], stick insect [22] and laboratory Drosophila hybrid [23]. On the other hand, in a large number of artificial triploidization studies in fish, an occurrence of abnormal embryos with haploid-like external appearance has been often reported in the treatment shortly after fertilization. In experiments to produce triploid salmonids, haploid embryos were cytogenetically recognized in heat-shocked groups [24,25] and pressure-shocked groups [25]. Such an incidence of haploid-like progeny was also reported in experiments to induce triploidy by inhibiting the second polar body release with cold-shock treatments shortly after fertilization in stickleback [26,27], common carp [28] and loach [29]. Although the origin of such unusual haploid-like progeny has not been well examined in these fish species, Ueda and Aoki [30] cytogenetically confirmed one androgenetic haploid embryo out of ten diploid hybrid embryos developing from cold shock $\left(0^{\circ} \mathrm{C}\right.$ for $\left.60 \mathrm{~min}\right)$ at $2 \mathrm{~min}$ after fertilization of eggs from Rhodeus ocellatus ocellatus (Rosy bitterling) with sperm from Acheilognathus rhombea (Kanehira bitterling). They suggested induction as a possible mechanism for androgenesis by temperature control of fertilized eggs. However, further studies are required since their results are from a single trial and a small sample size.

Since it is difficult to achieve perfect elimination of chromosome fragments of egg nucleus in androgenetic induction by the regular method of egg irradiation with UV [4], temperature shock of eggs shortly after fertilization may provide a new, easy and simple method to induce androgenesis in fish species and presumably in other vertebrate species. However, at present, treatment conditions to induce androgenesis have not been optimized in any fish species and mechanisms underlying such a temperature-induced androgenesis have not been examined yet.

In the present study, we optimized the cold-shock condition among different temperature $\left(0,3,6\right.$ and $\left.9^{\circ} \mathrm{C}\right)$ for
60 min duration just after fertilization to induce androgenetic progeny in the loach using albino color phenotype (recessive trait) as the paternal genetic marker. Abnormal morphological characteristic (referred to as the haploid syndrome) is another marker of haploid development. Ploidy (haploidy, diploidy, triploidy or others) was determined by DNA content flow cytometry, and microsatellite genotypes were analyzed to confirm all-paternal inheritance in the putative androgenetic progeny. Next, in the selected cold-shock condition at $3^{\circ} \mathrm{C}$ for $60 \mathrm{~min}$ duration shortly after fertilization, six crosses were conducted using orange phenotype (recessive trait) as the paternal color marker. In cold-shocked eggs and resultant embryos, cytological and histological observations were then performed to disclose the mechanism responsible for the initiation of androgenetic development after the cold-shock treatment.

\section{Results}

\section{Cold-shock treatments and phenotypes of the resultant progeny}

Eggs were cold-shocked at $0,3,6$ or $9^{\circ} \mathrm{C}$ just after fertilization to optimize temperature conditions in the first experiments comprising five crosses (A to E). The percentages of fertilized eggs were generally high and were not significantly different among groups including control (Figure 1A). Groups cold-shocked at 0,3 , and $6^{\circ} \mathrm{C}$ gave significantly lower hatching rates $(8.1 \%-21.5 \%)$ when compared with control (69.9\%) (Figure 1B). Hatching rate $(52.4 \%)$ of $9^{\circ} \mathrm{C}$ cold-shock group was not significantly different from the control (Figure 1B). Normal wild-type with melanophores appeared in control (Figure 2A), while cold-shock treatments resulted in the significant occurrence of the abnormal albino phenotype (a color marker for all-paternal inheritance, or androgenesis) (Figure 2B), besides the dominant normal wildtype (Figure 2C). Very few normal albino fry appeared in cold-shocked groups (Figure 2D).

As shown in Figure 3, most hatched larvae were normal wild-type in control (98.8\%) and $9^{\circ} \mathrm{C}$ cold-shocked group (91.1\%). Frequencies of normal wild-type decreased in 0,3 and $6^{\circ} \mathrm{C}$ cold-shocked groups. Instead, abnormal wild-type larvae occurred in cold-shocked groups. High frequencies of abnormal albino fry were recorded in groups cold-shocked at $0^{\circ} \mathrm{C}(41.0 \%)$ and $3^{\circ} \mathrm{C}$ (33.9\%). Cold-shock at $6^{\circ} \mathrm{C}$ occasionally resulted in relatively lower rates of the abnormal albino (18.8\%). On the other hand, cold-shock at $9^{\circ} \mathrm{C}$ resulted in a very low percentage of albinos $(0.1 \%)$, if any. It must also be mentioned that in addition, a very small number of normal albino fry and abnormal albinos were seen in the cold-shocked groups $(0.1-0.3 \%)$ and control groups $(0.2 \%)$, respectively. 


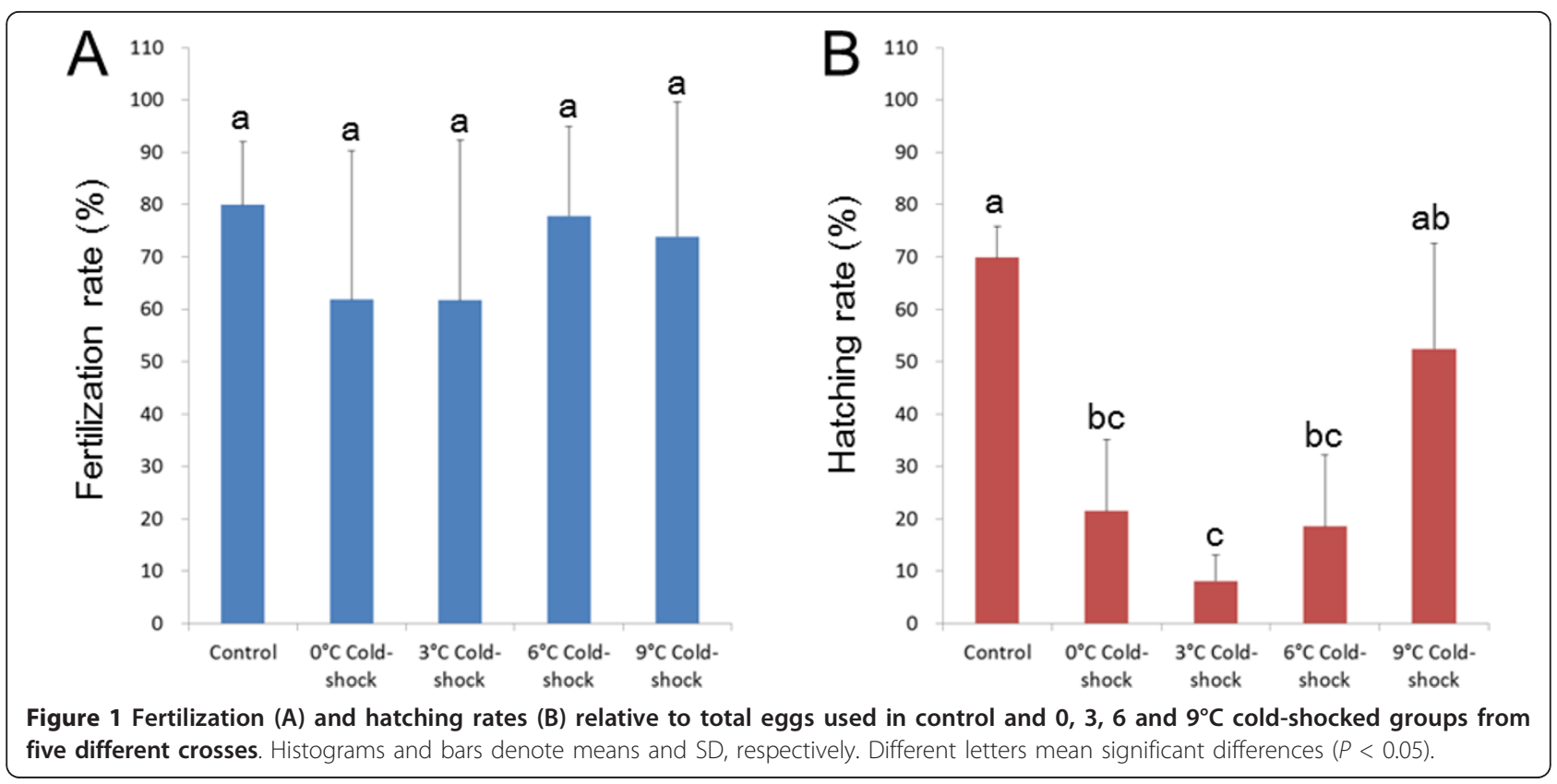

\section{Ploidy determination in progeny from cold-shock} treatments

Ploidy of normal wild-type, abnormal wild-type, normal albino and abnormal albino progeny from control and cold-shock treatments in five crosses (A to E) was assessed by flow cytometry (Table 1 Figure 4 ). In the controls, all the normal wild-type progeny were diploid (Figure 4A), whereas a few abnormal wild-type progeny contained haploid, diploid and hypodiploid progeny. A small number of abnormal albino phenotypes also appeared, but these were aneuploids with hypodiploid DNA content. In normal wild-type progeny from 0,3 and $6^{\circ} \mathrm{C}$ cold-shock treatments, both diploid and triploid (Figure 4B) progeny appeared, while those from $9^{\circ} \mathrm{C}$ group included only diploid individuals. Among the abnormal wild-type progeny from cold-shock treatments, haploid, diploid, triploid, aneuploid (Figure 4D) and mosaic (Figure 4EF) progeny appeared. All the abnormal albino progeny that appeared in 0,3 and $6^{\circ} \mathrm{C}$ cold-shock treatments were haploid (Figure $4 \mathrm{C}$ ), while very few normal albino progeny were diploid. Consequently, cold-shock just after fertilization often resulted in androgenetic haploid development, as shown by the appearance of abnormal albino phenotypes and haploid status in the progeny. In general, a high percentage of albino phenotype (putative androgenotes) was detected from the cold-shock treatment at 0 to $3^{\circ} \mathrm{C}$.

\section{Genetic verification of androgenesis by microsatellite genotyping}

Microsatellite genotyping was carried out at Mac60 and 63 loci [31] from normal wild-type diploid progeny from the control $(n=9)$, abnormal albino haploid progeny $(n=7)$, normal albino diploid progeny $(n=1)$, normal wild-type triploid progeny $(n=9)$, and abnormal wild type haploid progeny $(n=6)$ developing from the cold-shocked eggs in the cross A (Table 2). Although maternally and paternally derived alleles were segregated in normal wild-type diploid progeny according to Mendelian laws of inheritance, only paternal alleles were detected in abnormal haploid and normal diploid progeny with albino phenotype. Therefore, albino progeny were concluded to be androgenotes. Triploid wild-type progeny included two alleles of the mother and one allele of the father. Abnormal haploid progeny with wild-type phenotype included only maternally derived alleles and thus they are concluded to be sporadic gynogenetic haploid progeny.

\section{Production of androgenetic progeny by $3^{\circ} \mathrm{C}$ cold-shock}

Using a specific condition of the cold-shock $\left(3^{\circ} \mathrm{C}\right.$ for 60 min duration just after fertilization), eggs of wild-type females inseminated with sperm of orange (recessive trait) males were followed in the second experiment comprising six crosses ( $\mathrm{F}$ to $\mathrm{K}$ ). Fertilization rates were not significantly different between control (67.5\%) and cold-shocked group (61.1\%) (Figure 5A). Significantly lower hatching rate $(15.7 \%)$ was recorded from coldshocked group when compared to the control (56.5\%) (Figure 5B). High percentage of abnormal progeny with orange phenotype $(94.3 \%)$ was recorded only in coldshocked groups. In the control, most progeny (95.1\%) were normal exhibiting the wild-type phenotype, with a very few abnormal orange (1.2\%) and abnormal wildtype progeny (3.4\%) (Figure 6). 




Flow cytometry studies (Table 3 ) showed that a majority of normal wild-type progeny (133/134) and abnormal wild type progeny $(12 / 18)$ in the control were diploid and others were mosaics. On the other hand, both diploid (4/11) and triploid (7/11) progeny appeared in normal wild-type progeny from cold-shock treatments. Abnormal wild-type progeny in cold-shock were diploid $(1 / 3)$ and aneuploid (2/3). A large number of abnormal orange progeny in cold-shocked groups (108/109) and a small number of abnormal orange progeny in the control groups (3/5) were haploid except for a few aneuploids.

Normal diploid progeny with wild-type phenotype in the control and abnormal haploid progeny with orange color in the cold-shocked group from the two crosses (I and $\mathrm{K}$ ) were genotyped at three independent microsatellite loci [31], Mac 60, 402 and 519 (Table 4). Maternally and paternally derived alleles were segregated in the diploid progeny from the control, while only the paternally derived allele was detected in orange haploid progeny. These results indicate that abnormal orange progeny were androgenetic haploid developing from cold-shocked eggs.

\section{Cytological stages of DAPI stained nucleus in cold- shocked embryos}

DAPI-stained nuclear behavior in the progeny from the control is shown in Figure 7 and Table 5. Two or three condensed nuclei were observed in these embryos $10 \mathrm{~min}$ after fertilization (af), presumably the sperm nucleus, egg nucleus and/or second polar body nucleus (Figure 7A, Table 5). At $20 \mathrm{~min}$ af, the putative egg and sperm nucleus decondensed to form the two pronuclei (female and male), respectively (Figure 7B, Table 5), after which, the two pronuclei fused to form a decondensed pronucleus or a zygotic nucleus at $30 \mathrm{~min}$ af (Figure 7C, Table 5). At $40 \mathrm{~min}$ af, 


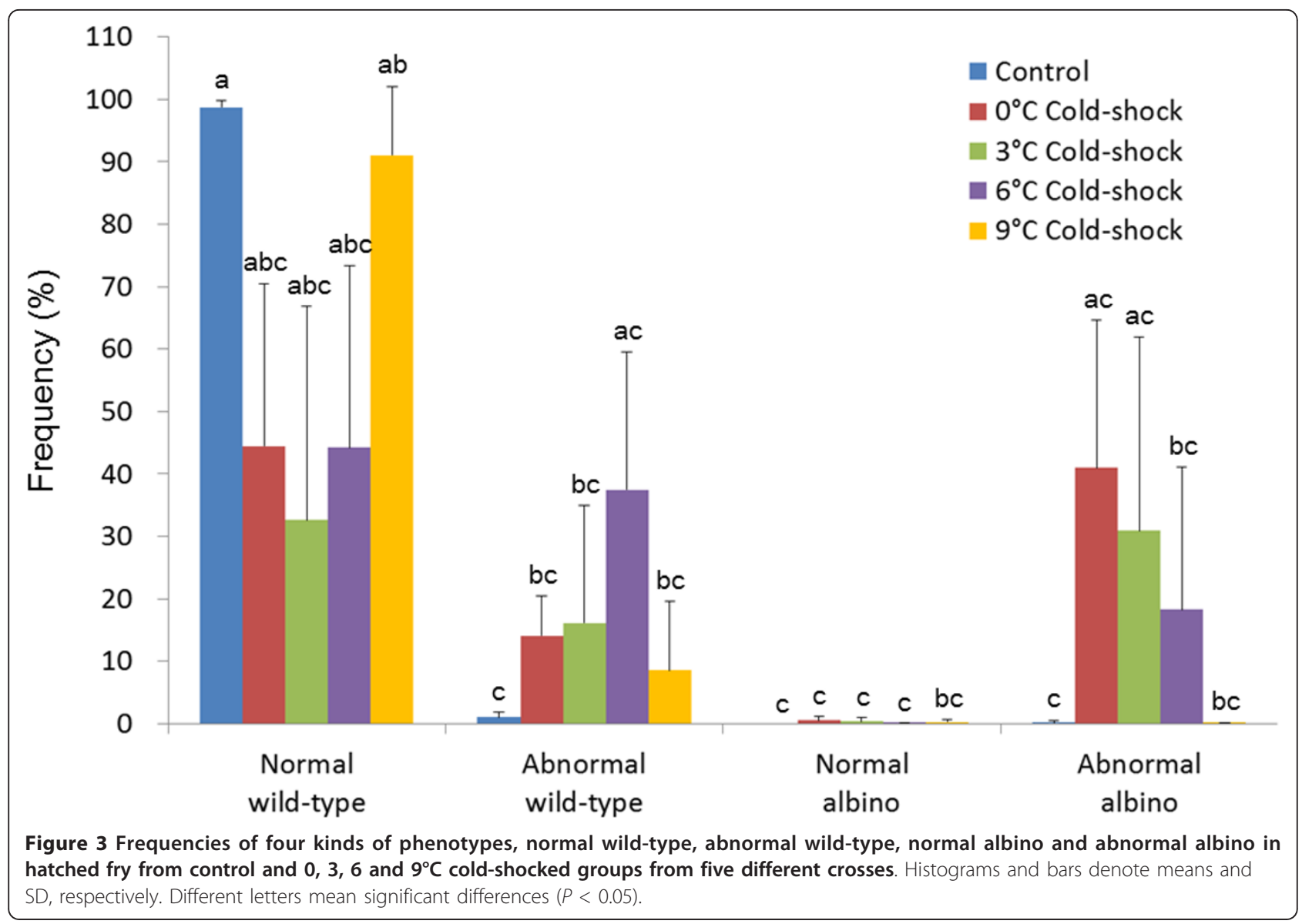

Table 1 Ploidy of fry from the control and cold-shocked eggs from the first experiment comprising five crosses (A to E)

\begin{tabular}{|c|c|c|c|c|c|c|c|c|c|c|c|}
\hline \multirow[t]{2}{*}{ Treatment } & \multirow[t]{2}{*}{ Phenotype } & \multirow[t]{2}{*}{ Morphology } & \multirow[t]{2}{*}{ No. of fry } & \multicolumn{8}{|c|}{ Ploidy status } \\
\hline & & & & $1 n$ & $2 n$ & $3 n$ & $6 n$ & Hypo-2n & Hyper-2n & Euploid mosaic & Aneuploid mosaic \\
\hline \multirow[t]{3}{*}{ Control } & Wild-type & Normal & 74 & 0 & 74 & 0 & 0 & 0 & 0 & 0 & 0 \\
\hline & Wild-type & Abnormal & 7 & 1 & 1 & 0 & 0 & $5^{1}$ & 0 & 0 & 0 \\
\hline & Albino & Abnormal & 2 & 0 & 0 & 0 & 0 & $2^{2}$ & 0 & 0 & 0 \\
\hline \multirow[t]{4}{*}{$0^{\circ} \mathrm{C}$ Cold-shock } & Wild-type & Normal & 71 & 0 & 18 & 53 & 0 & 0 & 0 & 0 & 0 \\
\hline & Wild type & Abnormal & 38 & 5 & 18 & 5 & 0 & $5^{3}$ & $2^{4}$ & $2^{5}$ & $1^{6}$ \\
\hline & Albino & Normal & 1 & 0 & 1 & 0 & 0 & 0 & 0 & 0 & 0 \\
\hline & Albino & Abnormal & 83 & 83 & 0 & 0 & 0 & 0 & 0 & 0 & 0 \\
\hline \multirow[t]{3}{*}{$3^{\circ} \mathrm{C}$ Cold-shock } & Wild-type & Normal & 32 & 0 & 2 & 29 & 1 & 0 & 0 & 0 & 0 \\
\hline & Wild-type & Abnormal & 24 & 2 & 6 & 5 & 0 & 0 & $10^{7}$ & 0 & $1^{8}$ \\
\hline & Albino & Abnormal & 62 & 62 & 0 & 0 & 0 & 0 & 0 & 0 & 0 \\
\hline \multirow[t]{4}{*}{$6^{\circ} \mathrm{C}$ Cold-shock } & Wild-type & Normal & 46 & 0 & 26 & 14 & 0 & 0 & 0 & $4^{9}$ & $2^{10}$ \\
\hline & Wild-type & Abnormal & 35 & 10 & 7 & 2 & 0 & $4^{11}$ & $6^{12}$ & $1^{13}$ & $5^{14}$ \\
\hline & Albino & Normal & 1 & 0 & 1 & 0 & 0 & 0 & 0 & 0 & 0 \\
\hline & Albino & Abnormal & 51 & 51 & 0 & 0 & 0 & 0 & 0 & 0 & 0 \\
\hline \multirow[t]{2}{*}{$9^{\circ} \mathrm{C}$ Cold-shock } & Wild-type & Normal & 40 & 0 & 40 & 0 & 0 & 0 & 0 & 0 & 0 \\
\hline & Wild-type & Abnormal & 4 & 0 & 2 & 0 & 0 & 0 & $1^{15}$ & 0 & $1^{16}$ \\
\hline
\end{tabular}

${ }^{1} 1.8 \mathrm{n}\left(2\right.$ individuals), $1.7 \mathrm{n}(1), 1.6 \mathrm{n}(1), 1.4 \mathrm{n}(1) ;{ }^{2} 1.8 \mathrm{n}(1), 1.6 \mathrm{n}(1) ;{ }^{3} 1.8 \mathrm{n}(3), 1.9 \mathrm{n}(1), 1.6 \mathrm{n}(1) ;{ }^{4} 2.1 \mathrm{n}(1), 2.5 \mathrm{n}(1) ;{ }^{5} 1 \mathrm{n}-3 \mathrm{n}(1), 1 \mathrm{n}-5 \mathrm{n}(1) ;{ }^{6} 2 \mathrm{n}-2.2 \mathrm{n}(1) ;{ }^{7} 2.2 \mathrm{n}(2), 2.3 \mathrm{n}(2)$, $2.4 \mathrm{n}(1), 2.6 \mathrm{n}(2), 2.8 \mathrm{n}(1), 2.9 \mathrm{n}(2) ;{ }^{8} 2.8 \mathrm{n}-3.2 \mathrm{n} ;{ }^{9} 1 \mathrm{n}-2 \mathrm{n}(2), 2 \mathrm{n}-3 \mathrm{n}(2) ;{ }^{10} \mathrm{2n}-2.1 \mathrm{n}(1), 1.9 \mathrm{n}-2.9 \mathrm{n}(1) ;{ }^{11} 1.9 \mathrm{n}(1), 1.8 \mathrm{n}(1), 1.7 \mathrm{n}(1), 1.3 \mathrm{n}(1) ;{ }^{12} 2.8 \mathrm{n}(1), 2.7 \mathrm{n}(1), 2.6 \mathrm{n}(1), 2.5 \mathrm{n}(1)$, $2.4 n(1), 2.2 n(1) ;{ }^{13} 2 n-3 n(1) ;{ }^{14} 1.8 n-2 n(1), 2.6 n-3 n(1), 1.7 n-2 n(1), 2 n-2.3 n(1), 1 n-1.1 n(1) ;{ }^{15} 2.2 n(1) ;{ }^{16} 1.3 n-2.9 n(1)$. 


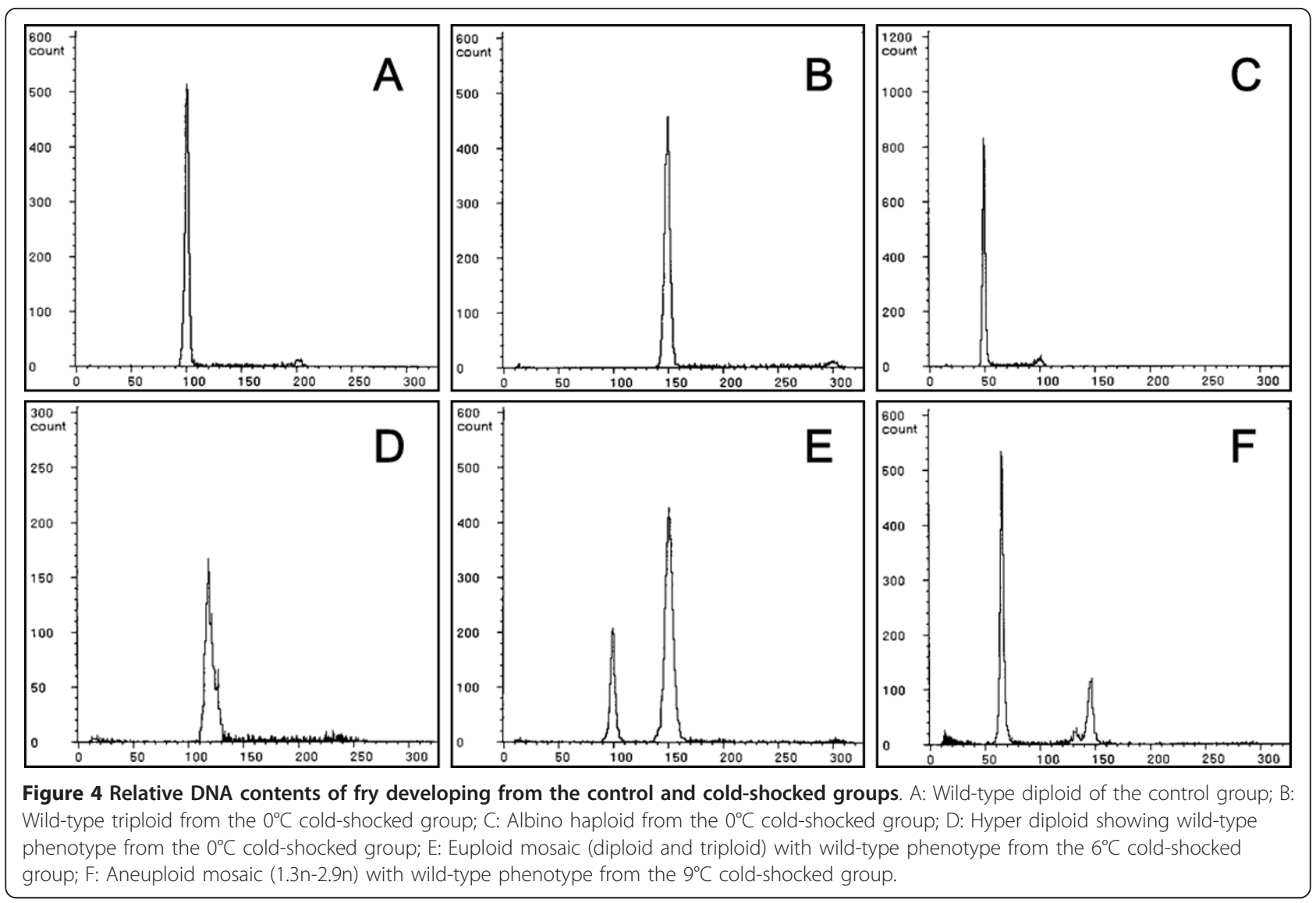

first cleavage anaphase was observed (Figure 7D, Table 5), and the nucleus became difficult to detect at $50 \mathrm{~min}$ af. However, the cleavage furrow was detected and the embryos entered into the two-cell stage at $60 \mathrm{~min}$ af (Figure not shown, Table 5).

In the cold-shock treatment one to three condensed nuclei were observed within $60 \mathrm{~min}$ af, (Figure 8A, Table 5). When compared to control embryos, these nuclei were strongly condensed and heavily stained, and two (Figure $8 \mathrm{~B}$ ) and/or three (Figure $8 \mathrm{C}$ ) condensed nuclei could still be seen until $120 \mathrm{~min}$ af. A decondensed pronucleus was firstly detected at $70 \mathrm{~min}$ af, together with two condensed nuclei (Figure 8D and 8E, Table 5). At $80 \mathrm{~min}$ af, embryos with one condensed nucleus and one decondensed pronucleus were seen (Figure 8F, Table 5), along with embryos with two decondensed pronuclei (Figure 4G) and those with only one decondensed pronuleus (Figure 8H, Table 5). Anaphase of the first cleavage was detected at $100 \mathrm{~min}$ af. At 100 and $110 \mathrm{~min}$ af, it was difficult to observe the behavior of the nucleus, but the two-cell stage was detected at $120 \mathrm{~min}$ af (Table 5).

\section{Histological observation of the nucleus in cold-shocked embryos}

In control embryos, the second polar body was released at $10 \mathrm{~min}$ af (Table 6), and the polar body nucleus and female (egg) nucleus were both observed (Figure 9A).

Table 2 Microsatellite Mac 60 and 63 genotypes of normal and abnormal progeny with wild or albino phenotypes developing from the control and cold-shocked eggs from a selected cross $A$ in the first experiment

\begin{tabular}{|c|c|c|c|c|c|c|c|c|c|c|c|c|c|c|}
\hline \multirow[t]{4}{*}{ Locus (LG) ${ }^{1}$} & \multirow{4}{*}{$\begin{array}{c}\text { Female } \\
\qquad(a / b)\end{array}$} & \multirow{4}{*}{$\begin{array}{l}\text { Male } \\
\text { (c/d) }\end{array}$} & \multicolumn{4}{|c|}{ Control } & \multicolumn{8}{|c|}{ Cold Shock } \\
\hline & & & \multicolumn{4}{|c|}{ Wild-type, Normal } & \multicolumn{2}{|c|}{ Albino, Abnormal } & \multirow{2}{*}{\multicolumn{2}{|c|}{$\frac{\text { Albino, Normal }}{\text { Diploid }}$}} & \multirow{2}{*}{\multicolumn{2}{|c|}{$\begin{array}{c}\text { Wild-type, Normal } \\
\text { Triploid }\end{array}$}} & \multirow{2}{*}{\multicolumn{2}{|c|}{$\frac{\text { Wild-type, Abnormal }}{\text { Haploid }}$}} \\
\hline & & & \multicolumn{4}{|c|}{ Diploid } & \multicolumn{2}{|c|}{ Haploid } & & & & & & \\
\hline & & & $a / c$ & $a / d$ & $b / c$ & $b / d$ & $c$ & $d$ & $c c$ & $d d$ & $a b c$ & $a b d$ & $a$ & $B$ \\
\hline Mac60 (LG4) & $128 / 135$ & $142 / 148$ & 4 & 2 & 2 & 1 & 3 & 4 & 1 & 0 & 5 & 4 & 3 & 3 \\
\hline Mac63 (LG4) & $125 / 138$ & $165 / 187$ & 3 & 2 & 2 & 2 & 5 & 2 & 0 & 1 & 5 & 4 & 3 & 3 \\
\hline
\end{tabular}

\footnotetext{
${ }^{1}$ Linkage group [31]
} 


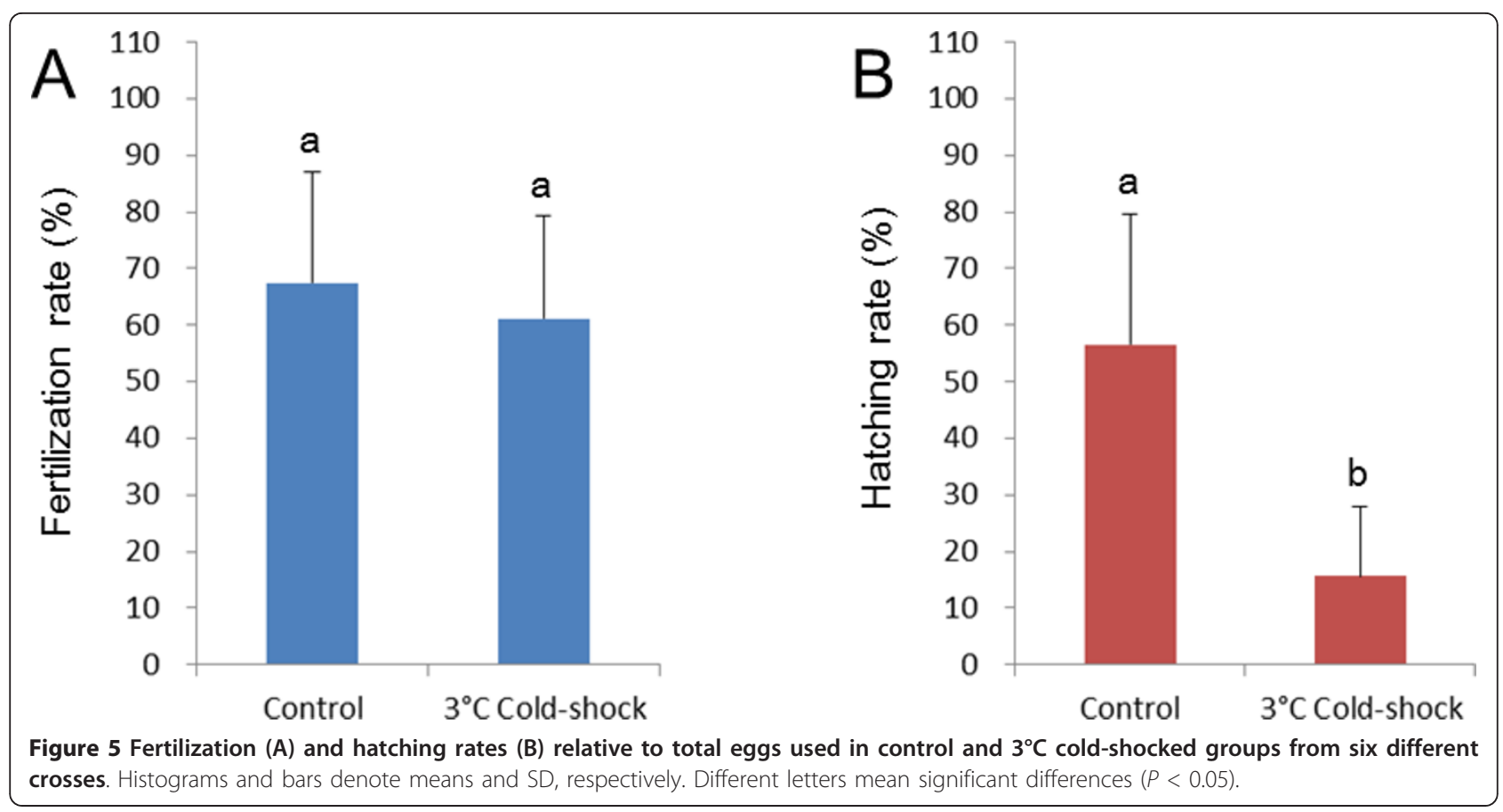

The female nucleus was located just underneath the second polar body nucleus in the egg, and the male (sperm) nucleus was located close to female nucleus in the same egg (Figure 9B). By $20 \mathrm{~min}$ af, the female and male pronuclei approached each other to fuse (Figure $9 \mathrm{C})$, thus revealing one or two decondensed pronuclei at this time (Table 6). Metaphase of the first cleavage was detected in $30 \mathrm{~min}$ af (Figure 9D, Table 6). Soon

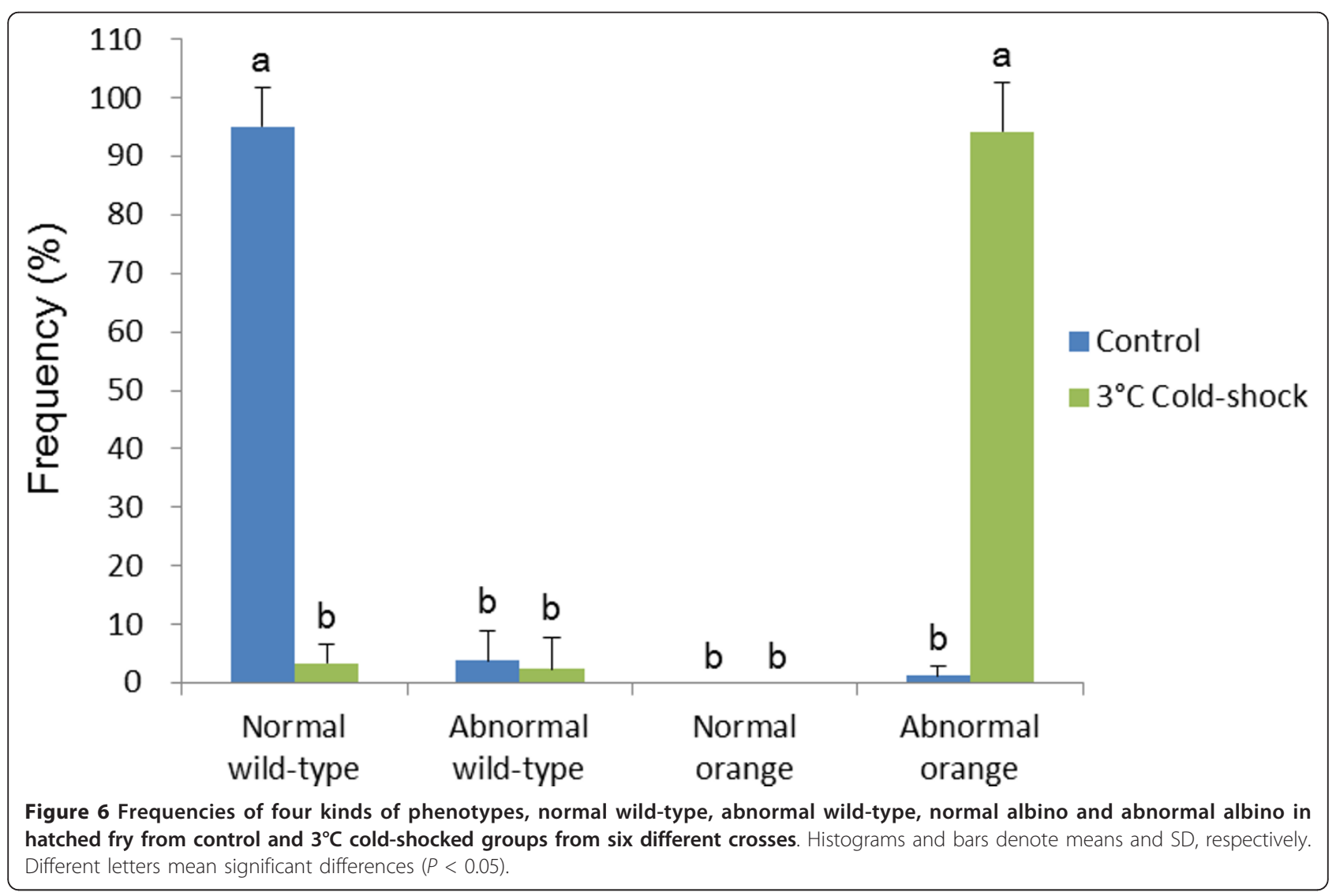


Table 3 Ploidy of fry from the control and cold-shocked eggs in the second experiment including six crosses (F to K).

\begin{tabular}{|c|c|c|c|c|c|c|c|c|c|c|}
\hline \multirow[t]{2}{*}{ Treatment } & \multirow[t]{2}{*}{ Phenotype } & \multirow[t]{2}{*}{ Morphology } & \multirow{2}{*}{$\begin{array}{l}\text { Fry } \\
\text { no. }\end{array}$} & \multirow[b]{2}{*}{$1 n$} & \multirow[b]{2}{*}{$2 n$} & \multirow[b]{2}{*}{$3 n$} & \multicolumn{4}{|c|}{ Ploidy status } \\
\hline & & & & & & & Hypo-2n & Hyper-2n & Euploid Mosaic & Aneuploid Mosaic \\
\hline \multirow[t]{3}{*}{ Control } & Wild-type & Normal & 134 & 0 & 133 & 0 & 0 & 0 & $1^{1}$ & $\mathrm{Cl}_{\mathrm{C}}$ \\
\hline & Wild-type & Abnormal & 18 & 0 & 12 & 0 & 0 & 0 & $5^{2}$ & $1^{3}$ \\
\hline & Orange & Abnormal & 5 & 3 & 0 & 0 & $2^{4}$ & 0 & 0 & 0 \\
\hline \multirow[t]{3}{*}{$3^{\circ} \mathrm{C}$ Cold shock } & Wild-type & Normal & 11 & 0 & 4 & 7 & 0 & 0 & 0 & 0 \\
\hline & Wild-type & Abnormal & 3 & 0 & 1 & 0 & 0 & $2^{5}$ & 0 & 0 \\
\hline & Orange & Abnormal & 109 & 108 & 0 & 0 & 0 & $1^{6}$ & 0 & 0 \\
\hline
\end{tabular}

${ }^{1} 1 \mathrm{n}-2 \mathrm{n}\left(1\right.$ individual); ${ }^{2} 1 \mathrm{n}-2 \mathrm{n}(3), 1 \mathrm{n}-3 \mathrm{n}(1), 1 \mathrm{n}-2 \mathrm{n}-3 \mathrm{n}(1) ;{ }^{3} 1.8 \mathrm{n}-2 \mathrm{n}(1) ;{ }^{4} 1.8 \mathrm{n}(2) ;{ }^{5} 2.6 \mathrm{n}(2) ;{ }^{6} 2.7 \mathrm{n}(1)$.

thereafter, anaphase of the first cleavage was detected within 30 and $40 \mathrm{~min}$ af (Figure 9E, Table 6). By $50 \mathrm{~min}$ af, pro-metaphase of the second cleavage was observed (Figure 9F, Table 6), and in $60 \mathrm{~min}$ af, the embryos reached anaphase of the second cleavage (Table 6).

In cold-shocked embryos, the second polar body was released within $70 \mathrm{~min}$ af, about $60 \mathrm{~min}$ later than the control (Table 6). Polar body extrusion could be categorized into four types based on histological observations: (1) the polar body was released and female (egg) nucleus was located just underneath the polar body (Figure 10A); (2) the polar body was released but no female nucleus was observed in the egg (Figure 10B); (3) the irregular metaphase equator was perpendicular to the surface of egg and nuclear material distributed from the egg surface to the polar body (Figure 10C); (4) the polar body release was suppressed and the nucleus (nuclei) remained in the egg (Figure 10D). At the same time (70 min af), a condensed nucleus, probably male nucleus, was also seen (Figure 10E), and in 10 more minutes (80 min af), a decondensed pronucleus emerged (Figure 10F). Within 90 min af, most embryos exhibited one decondensed pronucleus and the centriole replicated to form two asters or poles (Figure 10G), although two decondensed pronuclei were also detected in some eggs. Subsequently, in another $10 \mathrm{~min}(100 \mathrm{~min}$ af), the first cleavage occurred (Figure 10H), and by 110 and 120 min af, the first cleavage was completed resulting in two daughter nuclei (Table 6). The second cleavage followed (130 min af) (Table 6).

Besides the quasi-normal developing embryos mentioned above, various abnormal embryos were also observed in the cold-shocked group. The most frequent abnormality was seen in the form of anucler embryos (Table 6 Figure 11A-C), while other, less frequent, abnormalities were: a tripolar spindle configuration with a clumped nucleus and three asters (Figure 11D), spindles with a clumped nucleus and four asters (Figure $11 E$ ) and various other unusual embryos (Table 6).

\section{Discussion}

In most fish species except for salmonids, cold- or heatshock treatment of eggs for periods ranging from 2 to 10 min after fertilization often results in duplication of maternally derived chromosomes by inhibiting the release of the second polar body. Thus, gynogenetic diploid and wild-type triploid progeny occur in gynogenetically activated and normally fertilized eggs, respectively $[2,3]$. In the present study, both triploid and diploid wild-type progeny were also seen in the coldshocked groups after normal fertilization. Triploid wildtype progeny are presumably the result of the inhibiting

Table 4 Microsatellite genotyping using Mac 60, 402 and 519 loci of normal and abnormal progeny with wild or orange phenotypes developing from the control and cold-shocked eggs of two crosses ( $\mathrm{I}$ and $\mathrm{K}$ ) in the second experiment.

\begin{tabular}{|c|c|c|c|c|c|c|c|c|c|}
\hline \multirow[t]{4}{*}{ Exp. } & \multirow[t]{4}{*}{ Locus (LG) ${ }^{1}$} & \multirow{4}{*}{$\begin{array}{l}\text { Female } \\
(a / b \text { or } a / a)\end{array}$} & \multirow{4}{*}{$\begin{array}{c}\text { Male } \\
\text { (c/d or } c / c)\end{array}$} & \multirow{2}{*}{\multicolumn{4}{|c|}{$\begin{array}{c}\text { Control } \\
\text { Wild-type, } \\
\text { Normal }\end{array}$}} & \multicolumn{2}{|c|}{ Cold-shock } \\
\hline & & & & & & & & \multicolumn{2}{|c|}{ Orange, Abnorma } \\
\hline & & & & \multicolumn{4}{|c|}{ Diploid } & \multicolumn{2}{|c|}{ Haploid } \\
\hline & & & & $a / c$ & $a / d$ & $b / c$ & $b / d$ & c & $d$ \\
\hline \multirow[t]{3}{*}{ I } & Mac60(LG4) & $126 / 132$ & $124 / 124$ & 15 & 0 & 9 & 0 & 21 & 0 \\
\hline & Mac402(LG8) & $384 / 388$ & $370 / 373$ & 4 & 4 & 12 & 3 & 13 & 8 \\
\hline & Mac519(LG11) & $309 / 326$ & $254 / 344$ & 7 & 6 & 6 & 4 & 9 & 11 \\
\hline \multirow[t]{3}{*}{ K } & Mac60(LG4) & 131/133 & $124 / 124$ & 6 & 0 & 17 & 0 & 19 & 0 \\
\hline & Mac402(LG8) & $401 / 401$ & $370 / 373$ & 13 & 9 & 0 & 0 & 14 & 5 \\
\hline & Mac519(LG11) & $277 / 309$ & $254 / 344$ & 6 & 8 & 4 & 4 & 10 & 9 \\
\hline
\end{tabular}




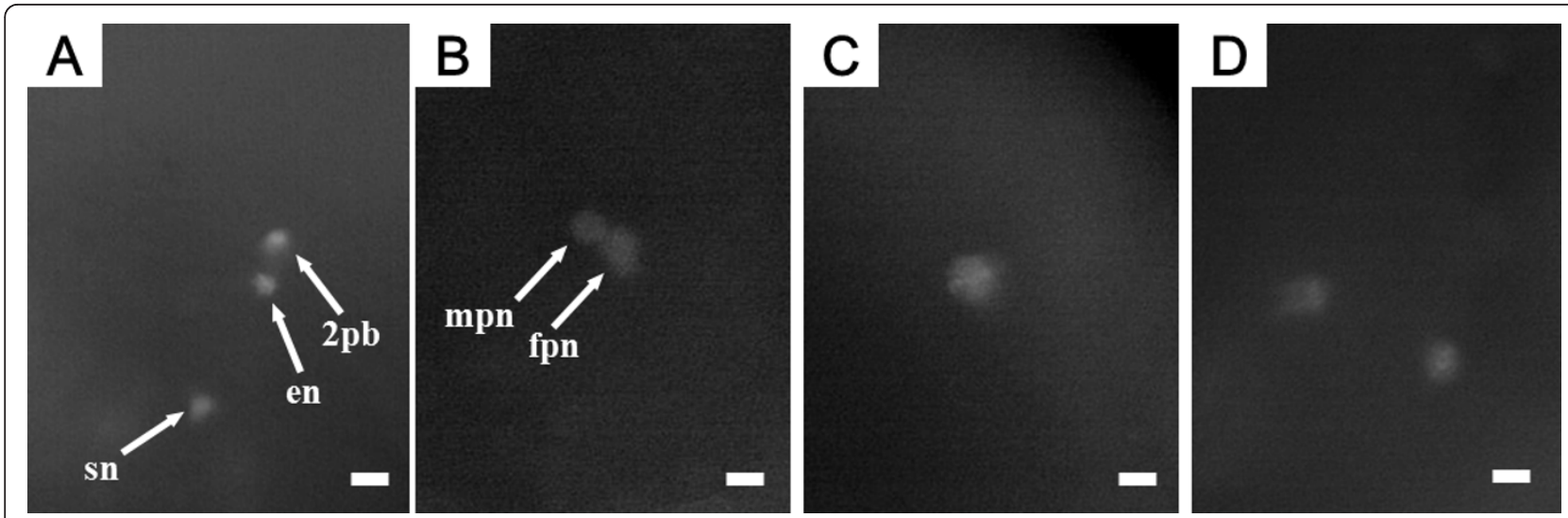

Figure 7 DAPI-stained nuclear behavior in eggs after fertilization in the control. A (10 min after fertilization; af): three condensed nuclei, sperm nucleus (sn), egg nucleus (en) and second polar body nucleus (2 pb); B (20 min af) two decondensed pronuclei, female pronucleus (fpn) and male pronucleus (mpn); C (30 min af) decondensed and fused one pronucleus; D (40 min af) anaphase of the first cleavage. Scale bars denotes $10 \mu \mathrm{m}$.

the release of the second polar body by cold-shock, because some triploid progeny included two maternally derived microsatellite alleles. On the other hand, wildtype diploid progeny are considered escapees from the cold-shock treatment. Gynogenetically haploid, unusual aneuploids (hypo- and hyper-diploid) and mosaics (diploid-triploid, diploid-pentaploid, diploid-aneuploid, etc.) frequently appeared among abnormal wild-type progeny. These were presumed to be "side-effects" of the cold-shock treatment on cell-division and subsequent development of the eggs.

As shown by microscopic observation of DAPI-stained nucleus and histological sections, the second polar body release, formation of female and male pronucleus, fusion of the two pronuclei, first cleavage and second cleavage occurred in the loach 10, 20, 30, 40 and 60 min after fertilization, respectively. Interestingly, although our observation of the cytological processes after fertilization in the loach were essentially same in the control as previously reported [17], this was not the case for the coldshocked eggs, which were quite different in our study. During the cold-shock treatment, one, two or three condensed nuclei were observed. After the cold-shock treatment, histological investigation showed four types of second polar body extrusion.

Type 1 (presence of egg nucleus) where the egg nucleus transforms to female pronucleus and then fuses with male pronucleus to form the zygotic nucleus, resulting in normal diploid progeny. The histological image of this type is equivalent to DAPI-stained three condensed nuclei observed under a stereoscopic fluorescence microscope.

In type 2 (absence of egg nucleus), the egg nucleus is released from the egg together with second polar body

Table 5 Stages of DAPI-stained nuclear behavior in the control and cold-shocked eggs of the loach at specific time intervals after fertilization.

\begin{tabular}{|c|c|c|c|c|c|c|c|c|c|c|c|c|c|c|c|c|}
\hline \multirow[t]{3}{*}{ Stages } & \multicolumn{16}{|c|}{ Time elapsed after fertilization (min) } \\
\hline & \multicolumn{6}{|c|}{ Control } & \multicolumn{10}{|c|}{ Cold-shock } \\
\hline & 10 & 20 & 30 & 40 & 50 & 60 & 10 & 30 & 60 & 70 & 80 & 90 & 100 & 110 & 120 & 130 \\
\hline 1 condensed nucleus & 0 & 0 & 0 & 0 & 0 & 0 & 5 & 3 & 6 & 11 & 6 & 6 & 1 & 4 & 1 & 0 \\
\hline 2 condensed nuclei & 4 & 0 & 0 & 0 & 0 & 0 & 12 & 16 & 15 & 5 & 11 & 4 & 3 & 1 & 1 & 0 \\
\hline 3 condensed nuclei & 4 & 0 & 0 & 0 & 0 & 0 & 3 & 0 & 0 & 8 & 3 & 0 & 1 & 0 & 0 & 0 \\
\hline 2 condensed nuclei +1 decondensed pronucleus & 0 & 0 & 0 & 0 & 0 & 0 & 0 & 0 & 0 & 2 & 2 & 0 & 0 & 0 & 1 & 0 \\
\hline 1 condensed nucleus +1 decondensed pronucleus & 0 & 0 & 0 & 0 & 0 & 0 & 0 & 0 & 0 & 0 & 5 & 5 & 1 & 0 & 0 & 0 \\
\hline 2 decondensed pronuclei & 0 & 6 & 1 & 0 & 0 & 0 & 0 & 0 & 0 & 0 & 2 & 1 & 0 & 0 & 0 & 0 \\
\hline 1 decondensed pronucleus & 0 & 3 & 4 & 1 & 1 & 0 & 0 & 0 & 0 & 0 & 2 & 3 & 1 & 0 & 1 & 0 \\
\hline First cleavage Anaphase & 0 & 0 & 0 & 4 & 1 & 0 & 0 & 0 & 0 & 0 & 0 & 0 & 1 & 0 & 0 & 0 \\
\hline 2-cell stage & 0 & 0 & 0 & 0 & 1 & 11 & 0 & 0 & 0 & 0 & 0 & 0 & 0 & 0 & 3 & 9 \\
\hline Others $^{1}$ & 0 & 0 & 2 & 2 & 4 & 0 & 0 & 1 & 0 & 0 & 1 & 6 & 6 & 16 & 5 & 0 \\
\hline Total number of eggs observed & 8 & 9 & 7 & 7 & 7 & 11 & 20 & 20 & 21 & 26 & 32 & 25 & 14 & 21 & 12 & 9 \\
\hline
\end{tabular}

\footnotetext{
${ }^{1}$ cytological observation could not be made.
} 


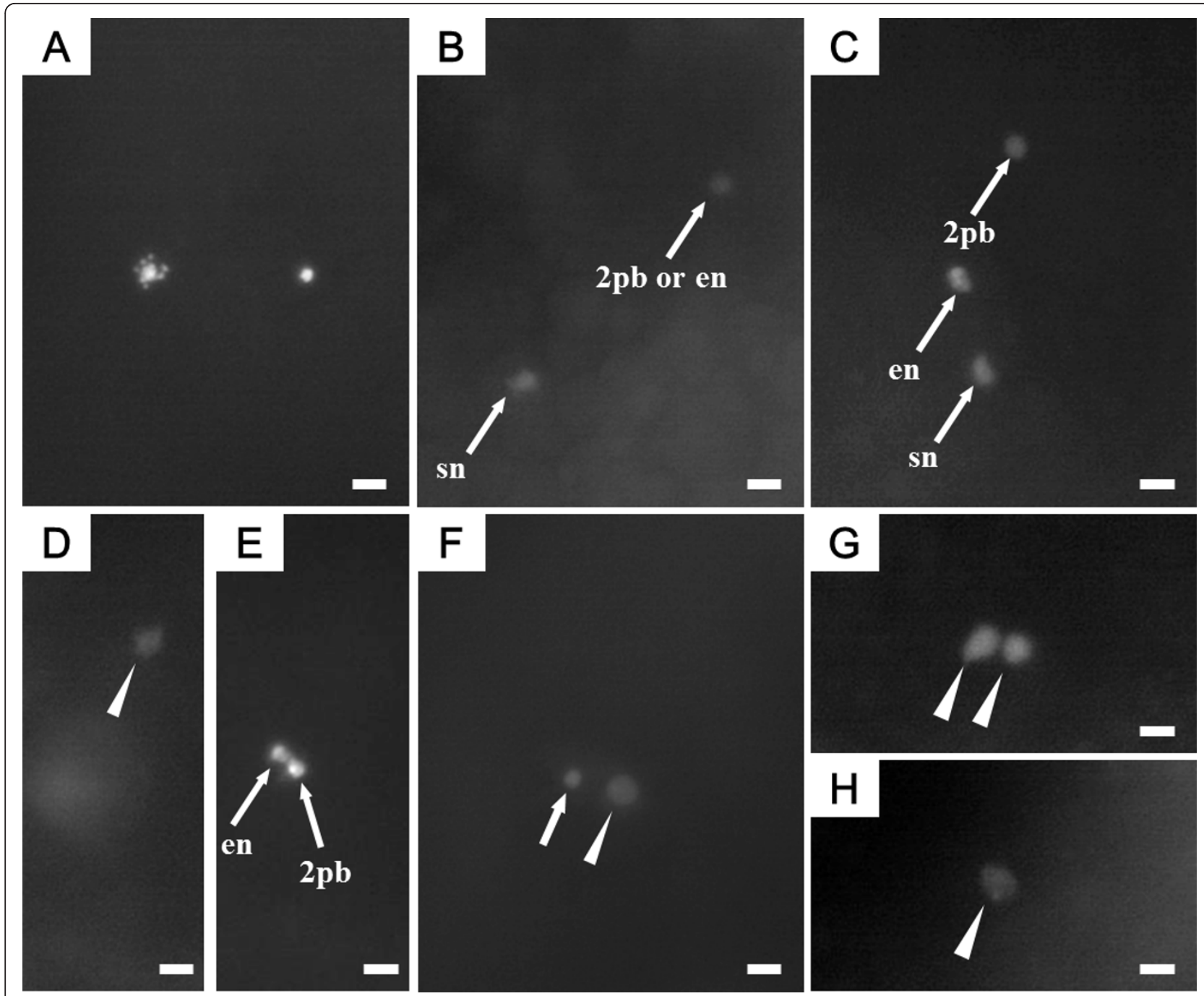

Figure 8 DAPI-stained nuclear behavior in cold-shocked eggs after fertilization. Arrows indicate condensed nuclei. Arrowheads indicate decondensed pronuclei. A (60 min after fertilization (af); just after the cold-shock treatment): two condensed nuclei, egg nucleus and sperm nucleus; B (70 min af): two condensed nuclei, sperm nucleus (sn) and egg nucleus (en) or second polar body nucleus (2 pb); C (80 min af): three condensed nuclei, sperm nucleus, egg nucleus and second polar body nucleus; D (70 min af): one decondensed male pronucleus, section from the same egg shown in $E_{;} E$ (70 min af): two condensed nuclei, egg nucleus and second polar body nucleus; $F$ ( 90 min af): one condensed nucleus and one decondensed pronucleus; G (90 min af): two decondensed pronuclei; H (90 min af): one decondensed pronucleus. Scale bars denote $10 \mu \mathrm{m}$.

nucleus and only the sperm nucleus remains in the egg. In other words, the polar body nucleus and the egg nucleus are both likely enclosed with the polar body and then released together. The histological image of this type is equivalent to DAPI-stained two condensed nuclei.

Type 3 (abnormal nucleus) is a transition stage that disturbs the polar body release to cause complete or partial elimination of the egg nucleus. Such a process gives rise to the type 2 category of polar body extrusion or development of aneuploid embryos.

Type 4 is the successful result of inhibition of the second polar body release and thus the polar body nucleus and egg nucleus are both enclosed in the egg, resulting in triploid progeny after fusion with the sperm nucleus. In the controls, two decondensed nuclei, i.e. female and male pronucleus, were detected, which then fused to become one decondensed pronucleus, while in coldshocked group, eggs with two pronuclei and those with one pronucleus were both observed at essentially the same time.

The conditions of the control clearly induce normal pronuclear fusion to form diploid or triploid progeny, while the cold-shock typically results in the existence of only the male pronucleus in the eggs, giving rise to androgenetic haploid progeny. However, the cold-shock 
Table 6 Cytological stages of H-E stained nuclear behavior in the control and cold-shocked eggs of the loach at specific time intervals after fertilization.

\begin{tabular}{|c|c|c|c|c|c|c|c|c|c|c|c|c|c|c|}
\hline \multicolumn{2}{|l|}{ Stages } & \multicolumn{13}{|c|}{ Time elapsed after fertilization (min) } \\
\hline & & \multicolumn{6}{|c|}{ Control } & \multicolumn{7}{|c|}{ Cold-shock } \\
\hline & & 10 & 20 & 30 & 40 & 50 & 60 & 70 & 80 & 90 & 100 & 110 & 120 & 130 \\
\hline \multirow[t]{4}{*}{ Second polar body release } & Female nucleus $(+)$ & 13 & 0 & 0 & 0 & 0 & 0 & 2 & 0 & 0 & 0 & 0 & 0 & 0 \\
\hline & Female nucleus (-) & 0 & 0 & 0 & 0 & 0 & 0 & 4 & 0 & 0 & 0 & 0 & 0 & 0 \\
\hline & Irregular division & 0 & 0 & 0 & 0 & 0 & 0 & 3 & 0 & 0 & 0 & 0 & 0 & 0 \\
\hline & Suppression & 0 & 0 & 0 & 0 & 0 & 0 & 4 & 0 & 0 & 0 & 0 & 0 & 0 \\
\hline 2 decondensed pronuclei & & 0 & 10 & 0 & 0 & 0 & 0 & 0 & 0 & 3 & 0 & 0 & 0 & 0 \\
\hline 1 decondensed pronucleus & & 0 & 6 & 0 & 0 & 0 & 0 & 0 & 3 & 10 & 0 & 5 & 0 & 0 \\
\hline \multirow[t]{3}{*}{ First cleavage } & Metaphase & 0 & 0 & 14 & 1 & 0 & 0 & 0 & 0 & 0 & 1 & 0 & 0 & 0 \\
\hline & Anaphase & 0 & 0 & 0 & 16 & 0 & 0 & 0 & 0 & 0 & 4 & 0 & 0 & 0 \\
\hline & Telophase & 0 & 0 & 0 & 2 & 0 & 0 & 0 & 0 & 0 & 0 & 5 & 3 & 0 \\
\hline \multirow[t]{2}{*}{ Second cleavage } & Metaphase & 0 & 0 & 0 & 0 & 22 & 0 & 0 & 0 & 0 & 0 & 0 & 0 & 1 \\
\hline & Anaphase & 0 & 0 & 0 & 0 & 0 & 15 & 0 & 0 & 0 & 0 & 0 & 0 & 1 \\
\hline Anuclear or Nuclear- & 1-cell & 0 & 0 & 0 & 0 & 0 & 2 & 3 & 5 & 8 & 8 & 4 & 0 & $1^{1}$ \\
\hline \multirow[t]{2}{*}{ Anuclear mosaic } & 2-cell & 0 & 0 & 0 & 0 & 0 & 0 & 0 & 0 & 0 & 0 & 0 & 8 & 18 \\
\hline & 3-cell & 0 & 0 & 0 & 0 & 0 & 0 & 0 & 0 & 0 & 0 & 0 & 0 & 2 \\
\hline \multicolumn{2}{|l|}{ Others } & 0 & 0 & 0 & 0 & 0 & 0 & 0 & 0 & 0 & $3^{2}$ & 0 & $7^{3}$ & $2^{4}$ \\
\hline \multicolumn{2}{|c|}{ Total number of eggs observed } & 13 & 16 & 14 & 19 & 22 & 17 & 16 & 8 & 21 & 16 & 14 & 18 & 25 \\
\hline
\end{tabular}

1 1-cell with anuclear nucleus with four asters.

2 1-cell embryo with a clumped nucleus.

${ }^{3}$ Second cleavage metaphase with a clumped nucleus (2 eggs), first cleavage metaphase with a clumped nucleus and three asters (1egg), first cleavage metaphase with a clumped nucleus and four asters (3 eggs), 1-cell with two decondensed pronuclei (1 egg).

${ }^{4}$ Second cleavage metaphase with excentric nuclear position (2 eggs).

treatment also appears to have serious side effects, giving rise to clumped nucleus, unusual polypolar spindle, and anuclear embryos. Such zygotes are supposed to develop into abnormal embryos and then die. Similar side effects have also been reported in the case of salmonid embryos that were manipulated to duplicate the chromosome set with heat shock [32,33] and hydrostatic pressure shock [6,34-36].

\section{Conclusions}

Cold-shock treatment (at 0 and $3^{\circ} \mathrm{C}$ ) of loach eggs for 60 min just after fertilization successfully induces androgenetic haploid development at relatively high frequencies among the survivors. Successful induction of haploid androgenesis was verified by external morphology (haploid syndrome), flow cytometry (haploid DNA content), color phenotype (paternally derived recessive albino or orange phenotype) and exclusive occurrence of paternally derived alleles in microsatellite DNA genotypes of the resultant progeny. The cytological mechanisms for androgenesis induced by cold-shock are explained as follows: the egg nucleus is presumably extruded together with the second polar body by the cold-shock treatment and thereby only sperm nucleus remains in the egg. Sperm nucleus transforms to male pronucleus and then initiates androgenetic development (Figure 12).
Successful induction of androgenesis by the coldshock may open new possibilities of chromosome manipulation. The next step in this application is the production of viable diploid androgenotes (very few survived in this study). However, the mechanism by which diploid androgenotes are generated is unknown. To obtain diploid androgenotes, chromosome duplication by inducing endomitosis at an early cleavage stage $[2,3,6-9,36]$ and the use of diploid sperm [10-15,35-41] are required to examine androgenesis after cold-shock. Another extension of this work is the application of the cold-shock androgenesis technique to other fish species.

\section{Methods}

\section{Ethics}

This study was performed in accordance with the Guide for the Care and Use of Laboratory Animals in Hokkaido University.

Fishes

Wild-type diploid loach Misgurnus anguillicaudatus were collected in Iwamizawa city, Hokkaido, Japan and stocked in the Aquarium center, Faculty of Fisheries Sciences, Hokkaido University, Hakodate city. Albino and orange loach strains (recessive traits) were also reared in the Aquarium center. For each cross, a single 


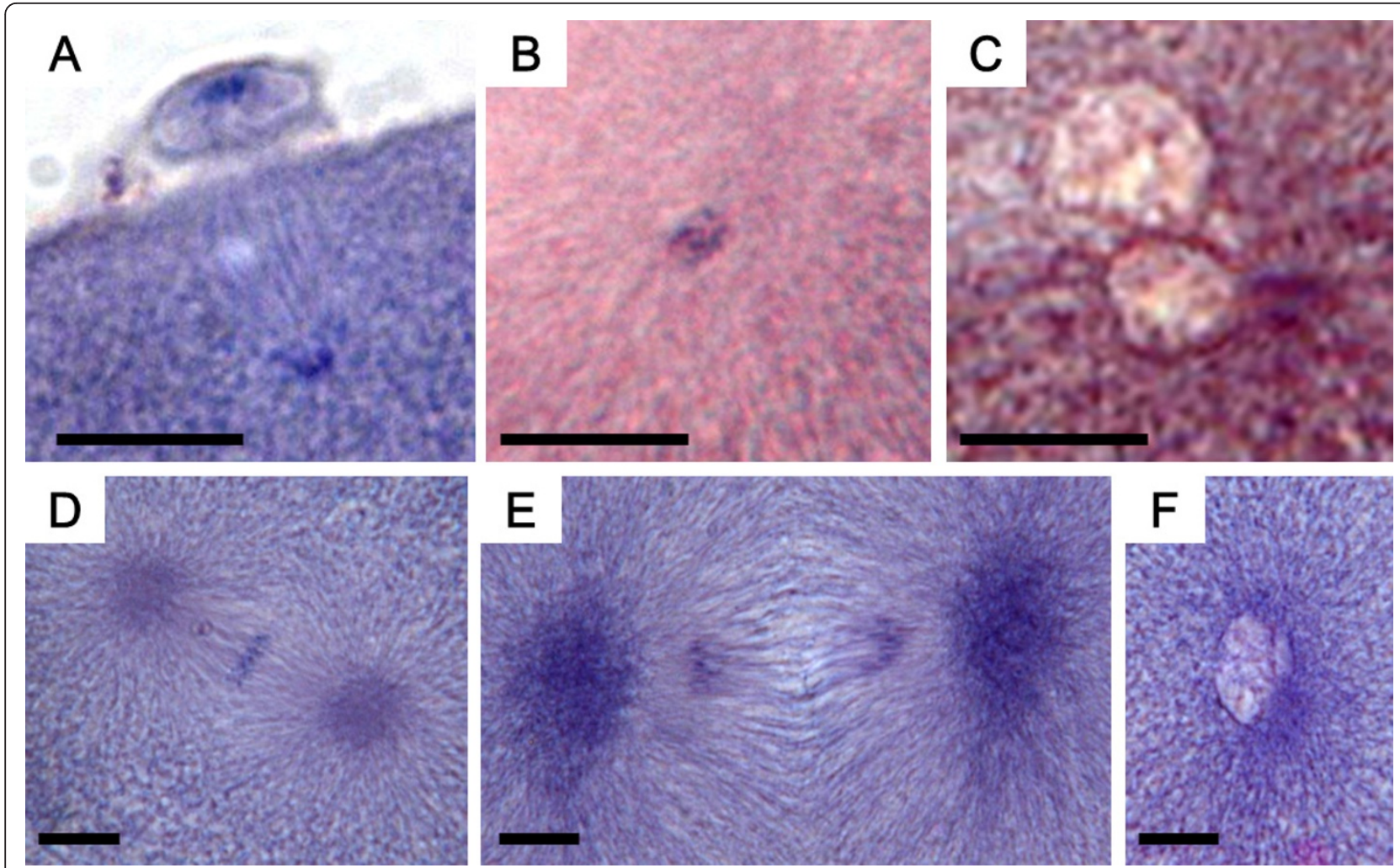

Figure 9 Histological sections of control eggs after fertilization. A (10 min after fertilization: af): second polar body released and egg nucleus present just underneath the polar body; B (10 min af): condensed sperm nucleus; C (20 min af): decondensed female and male pronuclei; D (30 min af): metaphase of first cleavage; E (40 min af): anaphase of first cleavage; F (50 min af): prophase of second cleavage. Scale bars denote $10 \mu \mathrm{m}$.

pair of loach (one wild-type female and one albino or orange male) was used.

\section{Cold-shock treatment}

Ovulation and spermiation were induced by intraperitoneal injection of human chorionic gonadotropin (20 IU/ g body weight, Aska Pharmaceutical Co. Ltd., Tokyo, Japan) as described in [42]. Eggs were collected on a polyvinylidene chloride film (SaranWrap: Asahi Kasei Co. Ltd., Tokyo, Japan) stretched over the bottom of a 90-mm diameter plastic dish. Sperm was collected into hematocrit tubes and diluted 1: 20 with Kurokura solution [43]. Eggs were mixed with diluted sperm and activated in ambient freshwater. In the first experiment to optimize cold-shock temperature among $0,3,6$ and $9^{\circ} \mathrm{C}$, five crosses (A to $\mathrm{E}$ ) were made. Average egg number was 307.8 for control and 831.8 for cold-shock. In the second experiment to confirm effectiveness of $3^{\circ} \mathrm{C}$ coldshock, six crosses (F to K) using different brood stock were made. Average egg number was 307.2 for control and 408.2 for cold-shock.

The plastic dish holding a batch of just-fertilized eggs on the film was transferred to a Styrofoam chamber containing cold freshwater with temperature adjusted to
$0,3,6$ or $9^{\circ} \mathrm{C}$. After a 60 min treatment, the plastic dish was placed in another chamber containing $20^{\circ} \mathrm{C}$ freshwater for $210 \mathrm{~min}$ after fertilization. Subsequently, the eggs were incubated in the plastic dish at $20^{\circ} \mathrm{C}$. A plastic dish with a batch of eggs that was transferred directly to the chamber with $20^{\circ} \mathrm{C}$ freshwater and placed there for $210 \mathrm{~min}$ after fertilization was used as control group.

\section{Rates of fertilization and hatching, and external appearance}

Fertilization rate was calculated within $4 \mathrm{~h}$ after fertilization as the proportion of cleaved eggs relative to the initial number of eggs used. Hatching rate was calculated as the proportion of hatched larvae relative to the initial number of eggs used. The rates of normal and abnormal larvae were calculated relative to the total number of hatched larvae. Color phenotypes (wild-type, albino and orange) were detected based on the expression of melanophores according to the procedure given in [4].

\section{Ploidy determination and microsatellite genotyping}

The DNA contents of hatched larvae were measured by flow cytometry based on the guidelines in [4]. Ploidy was determined by comparing the relative DNA content 


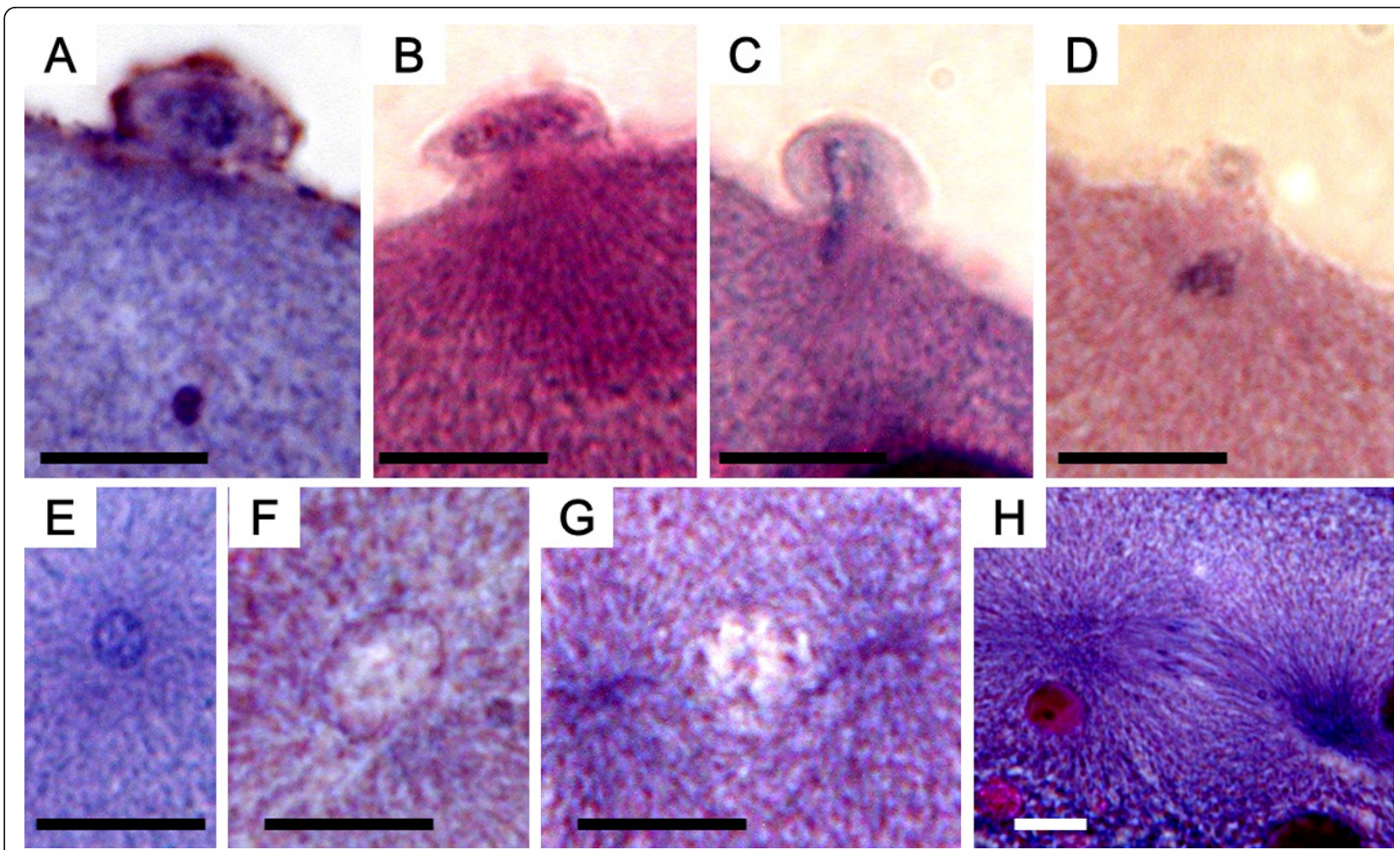

Figure 10 Histological sections of cold-shocked eggs after fertilization. A (70 min after fertilization: af): second polar body released and egg nucleus present just underneath the polar body; B (70 min af) second polar body present, but no egg nucleus; C (70 min af): abnormal extrusion of second polar body (note abnormal metaphase equator or nuclear substances ranging from egg surface to polar body); D (70 min af):

extrusion of second polar body suppressed; $E$ (70 min af): condensed sperm nucleus present; $F$ ( 80 min af): decondensed male pronucleus appears; G (90 min af): two asters seen; H (100 min af): anaphase of first cleavage. Scale bars denote $10 \mu \mathrm{m}$.

against a standard DNA content of the diploid loach. Genotyping was done for females, males and the progeny from control and cold-shocked groups at Mac60, 63,402 , and/or 519 loci according to the procedures outlined in [31].

\section{Cytological and histological examination}

Control and cold-shocked eggs for cytological observation were fixed with $4 \%$ paraformaldehyde dissolved in Phosphate Buffered Saline (PBS: $\mathrm{NaCl} 8$ g, $\mathrm{Na}_{2} \mathrm{HPO}_{4}-$ $12 \mathrm{H}_{2} \mathrm{O} 2.9 \mathrm{~g}, \mathrm{KCl} 0.2 \mathrm{~g}, \mathrm{KH}_{2} \mathrm{PO}_{4} 0.2 \mathrm{~g} / 1000 \mathrm{ml}$ double distilled water DDW) for $24 \mathrm{~h}$ and then transferred to PBS, then stored in a refrigerator $\left(4^{\circ} \mathrm{C}\right)$. The chorion was mechanically removed and the blastodisc stained for 30 min in the dark with a mixture of $10 \mu \mathrm{l}$ of DAPI (4'6-diamidino-2-phenylindole $1 \mathrm{mg} / 100 \mathrm{ml}(\mathrm{DDW})), 985 \mu \mathrm{l}$ of buffer A (Tris(hydroxyl-methyl)amino methane $0.124 \mathrm{~g}$, EDTA-2Na 0.3722 g, Nacl 0.5844 g/100 ml DDW-NaClEDTA buffer (pH7.4)) and $5 \mu \mathrm{l}$ of buffer B (2-mercaptoethylamine hydrochloride $0.1136 \mathrm{~g} / 100 \mathrm{ml} \mathrm{DDW})$. The samples were then rinsed twice with PBS for $10 \mathrm{~min}$ each, followed by one rinse for 2 min with $30 \%$ glycerol and $50 \%$ glycerol for $2 \mathrm{~min}$. Stained samples were observed using fluorescence microscope (Nikon ECLIPSE E800, Tokyo, Japan).

Eggs and embryos from control and cold-shocked groups were fixed with Bouin's fixative for $3 \mathrm{~h}$ and the fixed samples were stored in $80 \%$ ethanol. The samples were subsequently dehydrated and embedded in paraffin blocks. Sections were cut at $8 \mu \mathrm{m}$ thickness, stained with hematoxylin-eosin, and observed under microscope.

\section{Statistical analysis}

Data are shown as mean \pm S.D. Fertilization rates, hatching rates and phenotypic (external appearance and color trait) rates of fry classified with four types of morphological features in the first cold-shock experiment using $0,3,6$ and $9^{\circ} \mathrm{C}$ cold-shock temperatures and those in the second cold-shock experiment using the selected $3^{\circ} \mathrm{C}$ temperature were subjected to Kruskal-Walis tests. Subsequently, statistical significance was evaluated by means of a post-hoc multiple comparison using the Scheffé test. In the latter cold-shock treatment, fertilization rates and hatching rates were subjected to Mann-Whitney's U-test. Statistical significance was set at 0.05 . 

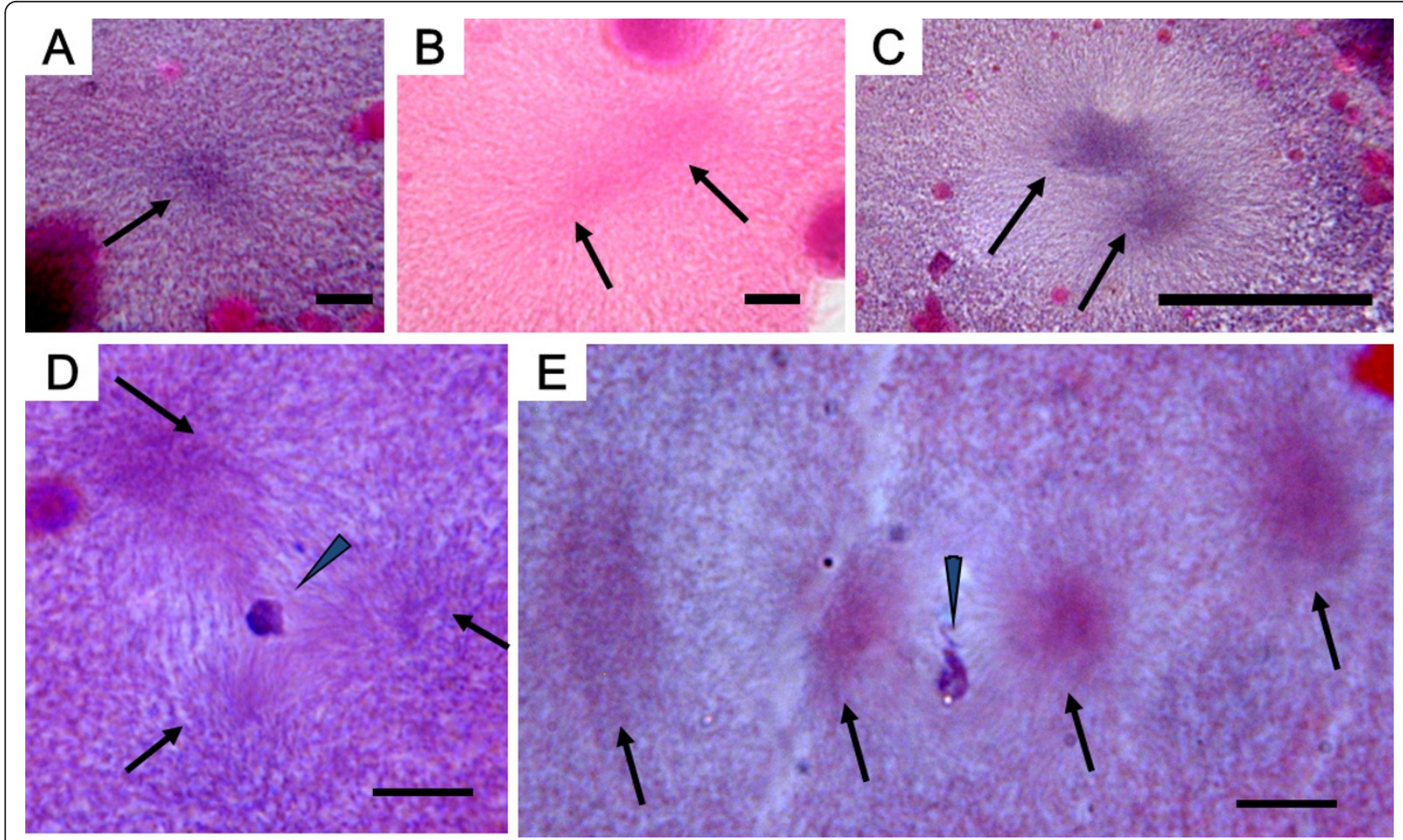

Figure 11 Histological sections showing abnormalities in cold-shocked eggs after fertilization (af). A (80 min af) anuclear cell with one aster (arrow); B (90 min af) anuclear cell with two asters (arrows); C (100 min af) anuclear cell with two asters (arrows); D (120 min af) cell with a clumped nucleus (arrowhead) and a tripolar spindle with three asters (arrows); E (120 min af) cell with a clumped nucleus (arrowhead) and four asters (arrows). Scales denote $10 \mu \mathrm{m}$.

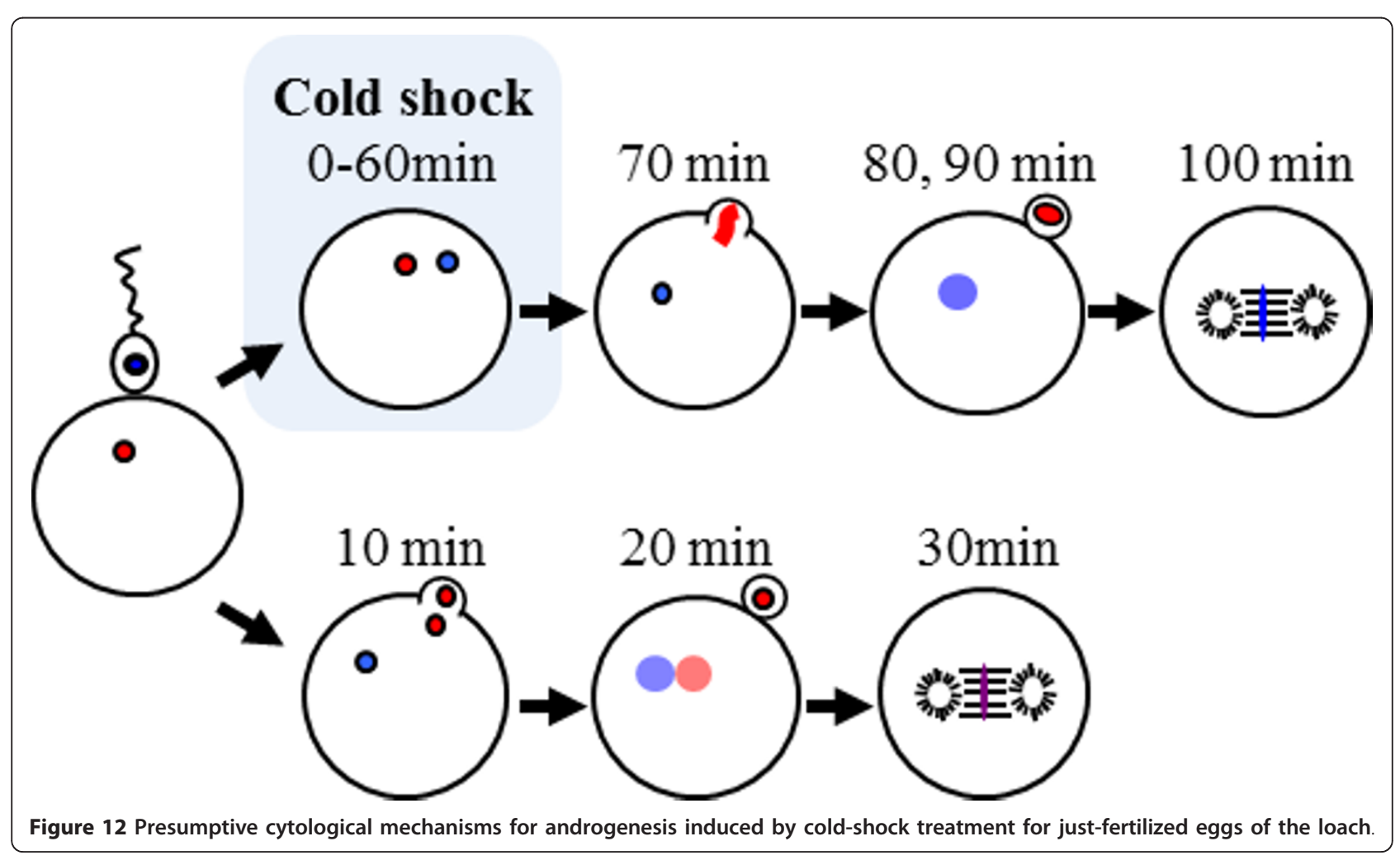




\section{Acknowledgements}

This research was supported in part by Grants-in-Aid for the $21^{\text {st }}$ Century COE Program (K-02, 2004-2008) from the Ministry of Education, Culture, Sports, Science and Technology (MEXT) and Scientific Research (B) (No.21380114) from the Japan Society for the Promotion of Science (JSPS).

\section{Author details}

${ }^{1}$ Laboratory of Aquaculture Genetics and Genomics, Faculty and Graduate School of Fisheries Sciences, Hokkaido University, 3-1-1, Minato, Hakodate, Hokkaido, 041-8611, Japan. ${ }^{2}$ Nanae Fresh-Water Laboratory, Field Science Center for Northern Biosphere, Hokkaido University, 2-9-1 Sakura-machi, Nanae, Hokkaido, 041-1105, Japan.

\section{Authors' contributions}

$K M, K A$, TF and EY designed research. KM, TF, MS and AK were in charge of fish breeding and experimental crossing. KM, MS and YZ performed molecular genotyping. TF and AK performed cytological observation. TF, KA and EY analyzed data and wrote the final drafts of the paper. All authors read and approved the final manuscript.

Received: 12 May 2011 Accepted: 29 November 2011

Published: 29 November 2011

\section{References}

1. Purdom C: Radiation-induced gynogenesis and androgenesis in fish. Heredity 1969, 24:431-444.

2. Pandian TJ, Koteeswaran R: Ploidy induction and sex control in fish. Hydrobiologia 1998, 384:167-243.

3. Komen $\mathrm{H}$, Thorgaard GH: Androgenesis, gynogenesis and the production of clones in fishes: a review. Aquaculture 2007, 269:150-173.

4. Fujimoto T, Sakao S, Yamaha E, Arai K: Evaluation of different doses of UV irradiation to loach eggs for genetic inactivation of the maternal genome. J Exp Zool Part A Ecol Genet Physiol 2007, 307:449-462.

5. Sakao S, Fujimoto T, Kimura S, Yamaha E, Arai K: Drastic mortality in tetraploid induction results from the elevation of ploidy in masu salmon Oncorhynchus masou. Aquaculture 2006, 252:147-160.

6. Bongers AB, In't Veld EPC, Abo-Hashema K, Bremmer IM, Eding EH, Komen J, Richter CJ): Androgenesis in common carp (Cyprinus carpio L.) using UV irradiation in a synthetic ovarian fluid and heat shocks. Aquaculture 1994, 122:119-132.

7. Sarder MRI, Penman DJ, Myers JM, MCAndrew BJ: Production and propagation of fully inbred clonal lines in the Nile tilapia (Oreochromis niloticus L). J Exp Zool 1999, 284:675-685.

8. Nagoya H, Okamoto H, Nakayama I, Araki K, Onozato H: Production of androgenetic diploids in amago salmon Oncorhynchus masou ishikawai. Fisherie Science 1996, 62:380-383.

9. Young WP, Wheeler PA, Field RD, Thorgaard GH: DNA fingerprinting confirms isogenicity of androgenetically derived rainbow trout line. Hered 1996, 87:77-81.

10. Yasui GS, Fujimoto T, Arai K: Restoration of the loach, Misgurnus anguillicaudatus, from cryopreserved diploid sperm and induced androgenesis. Aquaculture 2010, 308:S140-S144.

11. Nagoya H, Kawamura K, Ohta H: Production of androgenetic amago salmon Oncorhynchus masou ishikawe with dispermy fertilization. Fisheries Science 2010, 76:305-313.

12. Araki K, Shinma H, Nagoya H, Nakayama I, Onozato H: Androgenetic diploids of rainbow trout (Oncorhynchus mykiss) produced by fused sperm. Canadian Journal of Fisheries and Aquatic Sciences 1995, 52:892-896.

13. Kirankumar S, Pandian TJ: Use of heterologous sperm for the dispermic induction of androgenesis in barbs. J Fish Biol 2004, 64:1469-1484.

14. Clifton JD, Pandian TJ: Dispermic induction of interspecific androgenesis in the fish, Buenos Aires tetra using surrogate eggs of widow tetra. Current Science 2008, 95:64-74.

15. Grunina A, Recoubratsky AV, Tsvetkova LI, Barminstsev VA: Investigation on dispermic androgenesis in sturgeon fish. The first successful production of androgenetic sturgeons with cryopreserved sperm. International Journal of Refrigeration 2006, 29:379-386.

16. Yamashita M, Onozato H, Nakanishi T, Nagahama Y: Breakdown of the sperm nuclear envelope is a prerequisite for male pronucleus formation: direct evidence from the gynogenetic crucian carp Carassius auratus langsdorfii. Dev Biol 1990, 137:155-160.
17. Itono M, Okabayashi N, Morishima K, Fujimoto T, Yoshikawa H, Yamaha E, Arai $\mathrm{K}$ : Cytological mechanisms of gynogenesis and sperm incorporation in unreduced diploid eggs of the clonal loach, Misgurnus anguillicaudatus (Teleostei: Cobitidae). J Exp Zool Part A Ecol Genet Physiol 2007, 307:35-50

18. Dawley RM: An introduction to unisexual vertebrates. In Evolution and Ecology of Unisexual Vertebrates. Edited by: Dawley RM, Bogart JP. New York: New York State Museum Press; 1989:1-18.

19. Vrijenhoek RC, Dawley RM, Cole GJ, Bogart JP: A list of the known unisexual vertebrates. In Evolution and Ecology of Unisexual Vertebrates. Edited by: Dawley RM, Bogart JP. New York: New York State Museum Press; 1989:19-23.

20. Komaru A, Kawagishi T, Konishi K: Cytological evidence of spontaneous androgenesis in the freshwater clam Corbicula leana Prime. Dev Genes Evol 1998, 208:46-50.

21. Komaru A, Ookubo K, Kiyomoto M: All meiotic chromosomes and both centrosomes at spindle pole in the zygotes discarded as two polar bodies in clam Corbicula leana: unusual polar body formation observed by antitubulin immunofluorescence. Dev Genes Evol 2000, 210:263-269.

22. Mantovani B, Scali V: Hybridogenesis and androgenesis in the stick insect Bacillus rossius-grandii benazzii (Insecta, Phasmatodea). Evolution 1992, 46:783-796

23. Komma DJ, Endow SA: Haploidy and androgenesis in Drosophila. Proc Natl Acad Sci USA 1995, 92:11884-11888.

24. Arai K, Wilkins NP: Triploidization of brown trout (Salmo trutta) by heat shocks. Aquaculture 1987, 64:97-103.

25. Ueda T, Sato R, Kobayashi J: The origin on the genome of haploid masu salmon and rainbow trout recognized in abnormal embryos. Nippon Suisan Gakkaishi 1988, 54:619-625.

26. Swarup $\mathrm{H}$ : Production of heteroploidy in the three-spined stickle back (Gasterosteus aculeatus L). Nature 1956, 178:1124-1125.

27. Swarup H: Production of triploidy in Gasterosteus aculeatus (L). J Genet 1959, 56:129-141.

28. Gervai J, Peter S, Nagy A, Horvath L, Csanyi V: Induced triploidy in carp, Cyprinus carpio L. J Fish Biol 1980, 17:667-671.

29. Suzuki R, Nakanishi T, Oshiro T: Survival, growth and sterility of induced triploids in the cyprinid loach, Misgurnus anguillicaudatus. Bulletin of the Japanese Society of Scientific Fisheries 1985, 51:889-894.

30. Ueda T, Aoki K: The possibility of induction of androgenetic haploid embryos by an application of cold-shock shortly after fertilization in bitterling. Nippon Suisan Gakkaishi 1995, 61:245-246.

31. Morishima K, Nakayama I, Arai K: Genetic linkage map of the loach Misgurnus anguillicaudatus (Teleostei: cobitidae). Genetica 2008, 122:227-241.

32. Kobayashi T: Survival and cytological observation on early development of normal, hybrid and gynogenetic embryos of amago salmon. Fisheries Science 1997, 63:33-36.

33. Kobayashi T: Cytological observations on behavior of the nuclei after chromosome manipulation during early development of rainbow trout. Nippon Suisan Gakkaishi 1998, 64:782-791.

34. Yamazaki F, Goodier J: Cytogenetic effects of hydrostatic pressure treatment to suppress the first cleavage of salmon embryos. Aquaculture 1993, 110:51-59.

35. Sakao S, Fujimoto T, Tanaka M, Yamaha E, Arai K: Aberrant and arrested embryos from masu salmon eggs treated for tetraploidization by inhibition of the first cleavage. Nippon Suisan Gakkaishi 2003, 69:738-748.

36. Masaoka T, Arai K, Suzuki R: Production of androgenetic diploid loach Misgurnus anguillicaudatus from UV irradiated eggs by suppression of the first cleavage. Fisheries Science 1995, 61:716-717.

37. Thorgaard GH, Scheerer PD, Hershberger WK, Myers JM: Androgenetic rainbow trout produced using sperm from tetraploid males show improved survival. Aquaculture 1990, 85:215-221.

38. Arai K, Ikeno M, Suzuki R: Production of androgenetic diploid loach Misgurnus anguillicaudatus using spermatozoa of natural tetraploids. Aquaculture 1995, 137:131-138.

39. Morishima K, Oshima K, Horie S, Fujimoto T, Yamaha E, Arai K: Clonal diploid sperm of the diploid-triploid mosaic loach, Misgurnus anguillicaudatus (Teleostei: Cobitidae). J Exp Zool Part A Comp Exp Biol 2004, 301:502-511.

40. Yoshikawa H, Morishima K, Kusuda S, Yamaha E, Arai K: Diploid sperm produced by artificially sex-reversed clone loaches. J Exp Zool Part A Ecol Genet Physiol 2007, 307:75-83. 
41. Yoshikawa H, Morishima K, Fujimoto T, Saito T, Kobayashi T, Yamaha E, Arai $\mathrm{K}$ : Chromosome doubling in early spermatogonia produces diploid spermatozoa in a natural clonal fish. Biology of Reproduction 2009, 80:973-979.

42. Suzuki R, Yamaguchi M: Influence of water temperature on inducing spawning by hormone injection in the loach, cyprinid fish. Suisanzoshoku (Aquaculture Science) 1975, 22:135-139.

43. Kurokura H, Hirano R, Tomita M, Iwahashi M: Cryopreservation of carp sperm. Aquaculture 1984, 37:267-273.

doi:10.1186/1472-6750-11-116

Cite this article as: Morishima et al: Cold-shock eliminates female nucleus in fertilized eggs to induce androgenesis in the loach (Misgurnus anguillicaudatus), a teleost fish. BMC Biotechnology 2011 11:116.

Submit your next manuscript to BioMed Central and take full advantage of:

- Convenient online submission

- Thorough peer review

- No space constraints or color figure charges

- Immediate publication on acceptance

- Inclusion in PubMed, CAS, Scopus and Google Scholar

- Research which is freely available for redistribution

Submit your manuscript at www.biomedcentral.com/submit 